\title{
¿Utopía o leviatán? El papel del Estado en el magisterio social y en el pensamiento liberal
}

\author{
Gonzalo Villagrán Medina, S. I.'
}

Resumen: La actual situación de crisis nos obliga a preguntarnos sobre los límites del Estado de bienestar de las sociedades occidentales. De cara a iluminar esta reflexión este artículo presenta la reflexión sobre el papel del Estado en la sociedad tal como se ha desarrollado en el magisterio social. Para ayudar a concretar estas intuiciones a continuación se ponen en diálogo con dos pensadores de la escuela liberal: Friedrich Hayek y Amartya Sen. Este diálogo nos ayudará a entender la incompatibilidad de la postura del magisterio social con posiciones liberales radicales por suponer éstas una visión del hombre y de la sociedad opuesta a la de la tradición social católica. Por otra parte, la visión de Sen sí resulta muy compatible y nos puede ayudar a desarrollar principios de discernimiento para juzgar la presencia del Estado en la sociedad.

Palabras clave: Magisterio social, principio de subsidiariedad, socialización, sociedad civil, Friedrick Hayek, Amartya Sen, agencia.

Fecha de recepción: 30 de abril de 2014 .

Utopia or leviathan. Role of the state in social teaching and liberal thought

Abstract: The current crisis situation forces us to ask ourselves about the limits of the
Utopie ou Léviathan. Le rôle de l'État dans l'enseignement sociale et la pensée libérale

Résumé: La situation de crise actuelle nous oblige à nous interroger sur les limites de

${ }^{1}$ Facultad de Teología, Granada. 
Welfare State of well-being of Western societies. In order to illuminate this reflection this article presents the reflection on the role of the State in society as it has developed in the social teaching. To help realize these intuitions then are put in dialogue with two liberal school thinkers: Friedrich Hayek and Amartya Sen. This dialogue will help us understand the incompatibility of the position of the social teaching with liberal radical positions by assume are a vision of man and society opposed to the Catholic social tradition. On the other hand, the vision of Sen is very compatible and you can help us to develop principles of discernment to judge the presence of the State in society.

Key words: Social teaching, the principle of subsidiarity, socialization, society, Friedrich Hayek, Amartya Sen, agency.
l'État-Providence 4des sociétés occidentales. Pour éclairer cette réflexion cet article présente la réflexion sur le rôle de l'État dans la société telle qu'elle a développée dans le Magistère social. Pour aider à réaliser ces intuitions sont ensuite mises en dialogue avec deux penseurs de l'école libérale: Friedrich Hayek et Amartya Sen. Ce dialogue nous aidera à comprendre l'incompatibilité de la position du Magistère social avec libéral positions radicales en assument sont une vision de l'homme et la société opposée à la tradition sociale catholique. En revanche, la vision de Sen est très compatible et vous pouvez nous aider à développer les principes de discernement pour juger de la présence de l'État dans la société.

Mots clé: Enseignement sociale, principe de subsidiarité, socialisation, société, Friedrich Hayek, Amartya Sen, agence.

En un reciente programa de televisión se presentó un reportaje en el que se seguía los pasos a una persona que quería comenzar un negocio de envasado y comercialización de un producto que cultivaba. Tras acompañar al protagonista por todo tipo de oficinas oficiales y delegaciones el programa acababa haciendo balance: empezar un negocio nuevo y poner en práctica una iniciativa creativa había costado una cantidad casi mayor en informes y trámites que el coste de la maquinaria misma que necesitaba. Igualmente se terminaba mostrando un fajo de papeles de enorme grosor donde estaban todos los informes que había tenido que presentar a los diferentes organismos oficiales.

Por el contrario, son múltiples las campañas y movimientos ciudadanos en contra de los actuales recortes en sanidad que quitan la atención sanitaria gratuita a los extranjeros en situación de ilegalidad en España Estos movimientos ciudadanos consideran inaceptable quitar esta prestación al ser el derecho a la asistencia sanitaria un derecho humano básico. 
La presencia del Estado en la sociedad es un tema complejo y peliagudo que requiere un análisis fino. La actual situación de crisis obliga a reconsiderar el tamaño del Estado de bienestar de los países occidentales debido a la necesidad de reducir los gastos. Por tanto, es ahora más que nunca cuando es necesario una reflexión sobre qué criterios pueden indicarnos qué presencias del Estado en la sociedad son necesarias y cuáles superfluas e incluso nocivas. Necesitamos una reflexión sobre los límites del Estado de bienestar. La tradición social católica nos ofrece una sabiduría acumulada sobre este tema que podemos aprovechar. En los matices que descubrimos en el desarrollo de esta tradición podemos encontrar luces para orientar nuestra reflexión.

En este artículo señalaré primero cómo a partir de las encíclicas sociales de Juan Pablo Il se da una matización interesante en la comprensión del papel del Estado en la sociedad por parte de la doctrina social de la Iglesia. Dicha comprensión tiene un carácter histórico pues va respondiendo a las diferentes formas y funciones que se atribuyen al Estado en cada momento histórico y a la experiencia de éstas. Así si tras el Vaticano II el magisterio social dio un cierto respaldo a la intervención del Estado en la sociedad, la reserva que introduce Juan Pablo II debe entenderse como respuesta al peligro de anular la iniciativa privada ante una intervención del Estado que se había vuelto excesiva. La evolución posterior del magisterio social parece haber confirmado y continuado esa reserva de Juan Pablo II.

En un segundo momento pondré en diálogo estas intuiciones del magisterio social con el pensamiento de algunos pensadores actuales de la corriente liberal. El diálogo entre estas dos fuentes ayuda a profundizar y dar forma a las intuiciones que presenta el magisterio. En este sentido, mostraré primero cómo esta línea del magisterio social se puede prestar fácilmente a interpretaciones desde el liberalismo económico más radical, en la línea de Friedrich Hayek, que cambien su auténtico espíritu. Finalmente, mostraré cómo la comparación con una postura liberal más moderada como la de Amartya Sen es más fructífera. Esta comparación permite entender mejor el verdadero sentido del magisterio social de cara a establecer criterios sobre los límites del Estado de bienestar.

\section{Estado y sociedad civil en la Doctrina Social de la Iglesia}

La visión de la Iglesia sobre el papel del Estado en la sociedad se basa en la comprensión de Aristóteles de la política tal como ha sido recibida y reelaborada al interior de la tradición cristiana. Tal vez la mejor expresión moderna de esta 
tradición la representa Jacques Maritain quien en su libro El Hombre y el Estado explicita la diferencia entre el Estado y la sociedad, que él llama cuerpo político. Maritain afirma así que "[e]l Estado es tan sólo esa parte del cuerpo político cuyo peculiar objeto es mantener la ley, promover la prosperidad común y el orden público y administrar los asuntos públicos". Al ser una parte de la sociedad, el Estado ha de estar al servicio de la sociedad y no dominarla. Maritain lo afirmó con expresiones como al siguiente: "[e]l Estado es inferior al cuerpo político en cuanto todo, está al servicio del cuerpo político en cuanto todo".

La relación entre la sociedad civil y el Estado ha sido uno de los temas que ha estado en el centro del pensamiento social católico a lo largo de su historia, la razón es la necesaria, y no fácil, articulación de ambos ámbitos, el político y el civil. La comprensión de esta relación en el pensamiento social ha tenido un desarrollo progresivo respondiendo a los retos que cada momento histórico y modelo de estado planteaba. A pesar de la necesaria evolución y cambio, este desarrollo ha sido linear y coherente formulándose así un principio general para evaluar esta relación: el principio de subsidiariedad. Elaborado como respuesta a una situación histórica concreta-el Estado omnipresente de los totalitarismos de los años treintaeste principio se ha mostrado una buena síntesis de la posición de la Iglesia y ha adquirido un carácter permanente. Las matizaciones de dicho principio responden a la adaptación de la Doctrina Social a las diferentes realidades de las comunidades cristianas que Pablo VI formulaba en 1971 en Octogesima Adveniens 4.

Antes de pasar a estudiar las diferentes encíclicas, es especialmente importante tener en cuenta el contexto desde el cuál las leemos cuando nos preguntamos por el rol del Estado en la sociedad. La razón es el gran peligro de imponer la experiencia europea $u$ occidental a otras zonas de la Iglesia. Especialmente al tratar sobre el papel del Estado en la sociedad las diferencias entre los diversos continentes son muy grandes.

El principio de subsidiariedad fue formulado explícitamente en el pensamiento social católico en la encíclica Quadragesimo anno de 1931. En el contexto de esta encíclica el principio quiere responder al Estado totalitario del fascismo o el marxismo de la primera mitad del siglo XX que deja al individuo solo y aislado frente a un Estado omnipresente. Las fuentes teológicas que inspiran este principio son varias. En la Escritura cristiana encontramos varias llamadas a ejercer la autoridad como servicio y no como dominio. El Catecismo de la Iglesia Católica lo ilustra con la imagen de Dios que pudiendo ejercer todos los poderes ha querido dejar al hombre todas las funciones que éste pueda ejercer. En el contexto del magisterio social de la Iglesia este principio pide alcanzar un equilibrio entre la iniciativa 
de la sociedad y la iniciativa que viene del Estado. A lo largo de la historia del pensamiento social los documentos han ido escorándose más hacia un lado v otro en función de las necesidades que la realidad iba planteando. La aplicación del principio de subsidiariedad, por tanto, debe tener en cuenta el momento histórico así como el contexto social y económico concreto.

\section{I. La revalorización del papel del Estado en economía dentro de la doctrina social en los años 60}

Es claro que la lglesia desde un principio ha defendido el papel de la sociedad civil que a través de las diferentes asociaciones intermedias trabaja por el bien común. Ya en la encíclica Rerum Novarum a la vez que se invitaba al Estado a intervenir para subsanar problemas sociales, se defendía la bondad de la iniciativa asociativa en la sociedad civil frente al Estado. Este posicionamiento muestra la respuesta de la Iglesia a la ideología del Estado mínimo que defendía el liberalismo económico clásico del siglo XIX que era incapaz de hacer frente a la situación de miseria de los obreros industriales. Todo ello enmarcado en el proceso de clarificación del principio de subsidiariedad.

Sin embargo, es igualmente cierto que en tiempos pasados la doctrina social ha afirmado explícitamente lo mucho que se esperaba de la acción directa del Estado en la sociedad y en la economía animando a incrementar esta acción. Así en varios documentos encontramos llamadas muy fuertes a una vigorosa intervención estatal en la economía urgida por dicho principio de subsidiariedad. Por ejemplo en la encíclica Mater et Magistra (MM) de 1961 se pueden encontrar afirmaciones como la siguiente:

Sin embargo, por las razones que ya adujeron nuestros predecesores, es necesaria también la presencia activa del poder civil en esta materia, a fin de garantizar, como es debido, una producción creciente que promueva el progreso social y redunde en beneficio de todos los ciudadanos.

En su comentario a MM Marvin Mich identifica el contexto de la encíclica como un contexto de controversia en la Iglesia ante el surgimiento de los diferentes estados de bienestar tras la guerra mundial. Mich afirma que en esta situación Juan XXIII tomó posición sobre el tema en esta encíclica al, en sus palabras, "subrayar la importancia de la responsabilidad personal pero también... apoyando una papel intenso del Estado en la promoción del bien común de la sociedad y de toda persona". Mich afirma así que Juan XXIII defendió "un Estado activo en asuntos económicos" como forma de evitar el desempleo. Por tanto en MM el magisterio 
social reconoce una convergencia entre su visión de la sociedad y el proyecto incipiente de Estado de bienestar que surgía en aquel momento. Este Estado de bienestar iba a requerir una mayor presencia e intervención del Estado en la economía para ser llevado a cabo.

Esta toma de postura puede leerse con el trasfondo de la controversia sobre el término "socialización" que rodeó a la recepción de esta encíclica. A pesar de las prevenciones que Juan XXIII expresó frente a una socialización que eliminara la libertad del individuo, en general el papa Juan vio con buenos ojos la mayor presencia del Estado en la vida social que empezó a darse en los años de la posguerra.

Unos años más tarde en la encíclica Populorum Progressio (PP) Pablo VI se expresaba en términos similares. Aunque el contexto de esta encíclica, los esfuerzos por salir del subdesarrollo, era muy distinto al de MM, las afirmaciones sobre el papel del Estado iban en un sentido similar. Pablo VI afirmaba así que:

[I]a sola iniciativa individual y el simple juego de la competencia no serían suficientes para asegurar el éxito del desarrollo... Los programas son necesarios para "animar, estimular, coordinar, suplir e integrar»l la acción de los individuos y de los cuerpos intermedios. Toca a los poderes públicos escoger y ver el modo de imponer los objetivos que proponerse, las metas que hay que fijar, los medios para llegar a ella, estimulando al mismo tiempo todas las fuerzas, agrupadas en esta acción común.

Aunque MM y PP tienen contextos y autores distintos (Pietro Pavan y Louis-Joseph Lebret), es posible identificar una cierta inspiración común en ambas encíclicas. Así por ejemplo, el concepto de socialización que Pietro Pavan y Juan XXIII recogerán en $M M$ estaba también muy presente en la reflexión del grupo Economía y Humanismo al que pertenecía Louis-Joseph Lebret, O.P., gran inspirador de PP. Se percibe, por tanto, en ambas encíclicas una toma de postura de la doctrina social de los años 60 en favor de la corriente keynesiana que dominaba la economía de la mayor parte de los países del mundo occidental desde la Segunda Guerra Mundial.

Los cambios producidos en la economía y la sociedad a partir de la primera crisis del petróleo de 1973, especialmente la caída del muro de Berlín en 1989, han llevado a resaltar otros acentos en la doctrina social de la Iglesia en la interpretación del principio de subsidiariedad. 


\section{I.2. El principio de subsidiariedad en las encíclicas sociales de Juan Pablo II}

Daniel Finn en su comentario a la encíclica Centesimus Annus (CA), reconoce en el magisterio social de Juan Pablo Il un cambio de paradigma que quiere resaltar las ventajas de los mercados, el esfuerzo individual y la creatividad humanas. El marco histórico que explica este giro es la realidad del colectivismo marxista de los países del este europeo, que el Papa conocía bien y rechazaba profundamente. También, paralelamente, explica este giro la experiencia de las democracias occidentales que a la vez que crecen en servicios ofrecidos a sus ciudadanos van perdiendo espíritu y hondura en su vida social. Todo esto unido a la crisis del Estado de bienestar europeo que comienza con la crisis del petróleo de 1973. Este paradigma se concretaría en CA al intentar el papa presentar un programa para las economías occidentales y las economías de los países excomunistas que se alejara tanto del socialismo real como de los excesos del Estado de bienestar.

Este acento en la iniciativa de los individuos estaba presente desde el comienzo del magisterio social de Juan Pablo II pero de una forma muy germinal. Aunque en su primera encíclica social, Laborem Exercens de 1979, no hay demasiadas referencias explícitas al tema que nos ocupa aquí, sin embargo se puede percibir en ella un desarrollo del principio de subsidiariedad en oposición al modelo colectivista. En el número 14 Juan Pablo II critica "el monopolio de la administración y disposición de los medios de producción por parte del Estado" porque no realiza una auténtica "socialización" de los medios de producción sino que los deja en manos de un grupo concreto de personas. Una auténtica "socialización" para el sumo pontífice debe suponer que el trabajador "tenga pleno título a considerarse al mismo tiempo "copropietario» de esa especie de gran taller de trabajo en el que se compromete con todos". Para que esto se dé invita el Papa a que trabajo y capital se asocien en los diferentes cuerpos intermedios de la sociedad. En la descripción de estos cuerpos intermedios se puede ver la idea de espacio para iniciativa y la participación social que veremos que va describiendo la sociedad civil:

Cuerpos intermedios con finalidades económicas, sociales, culturales: cuerpos que gocen de una autonomía efectiva respecto a los poderes públicos, que persigan sus objetivos específicos manteniendo relaciones de colaboración leal y mutua, con subordinación a las exigencias del bien común y que ofrezcan forma y naturaleza de comunidades vivas; es decir, que los miembros respectivos sean considerados y tratados como personas y sean estimulados a tomar parte activa en la vida de dichas comunidades.

Unos años más tarde, aún en plena Guerra Fría, la encíclica Sollicitudo Rei Socialis (SRS) de 1987 trata el tema de la presencia del Estado en la sociedad de una manera indirecta. La preocupación no es tanto el principio de subsidiariedad tal cual sino el de participación de los ciudadanos en la vida pública y económica. Así, una 
de las líneas de ésta encíclica es mostrar como el subdesarrollo va más allá de las meras carencias económicas. En este sentido, Juan Pablo II denunciaba como una de las formas de subdesarrollo la carencia del derecho a la iniciativa económica. Si tenemos en cuenta el contexto de la encíclica, la guerra fría y la oposición de bloques, podemos entender que el pontífice estaba pensando especialmente en lo regímenes colectivistas. Sin embargo, la reflexión sobre las consecuencias de esta falta de iniciativa económica va más allá de la oposición de bloques e ilustra una situación de anulación de la creatividad individual en general. El papa ve en esta falta de iniciativa consecuencias como: la destrucción del espíritu de iniciativa y de la subjetividad creativa del ciudadano, la pasividad y dependencia del aparato burocrático, la frustración, la desesperación, y la emigración tanto física como psicológica. Tan importante es para Juan Pablo ll la falta del derecho a la iniciativa económica que lo situará al mismo nivel que algo tan importante para él como la falta del derecho a la libertad religiosa.

Pero donde el acento sobre la iniciativa individual se explicita completamente es en su encíclica Centessimus Anus de 1991, encíclica escrita como respuesta a la caída del muro de Berlín y del bloque comunista. En esta encíclica Juan Pablo II volvía sobre esta crítica a las consecuencias de un excesivo peso del Estado esta vez de forma más explícita. El contexto de la crítica era la afirmación de que las sociedades capitalistas basadas en el bienestar y el consumo, que se consideraban victoriosas frente al colectivismo, al reducir al hombre a sus necesidades materiales termina cayendo en un nuevo tipo de alienación.

En este contexto, Juan Pablo II identifica una dinámica en los últimos tiempos en sociedades occidentales de ampliación de la intervención del Estado en el sentido de lo que llama "Estado de bienestar". Juan Pablo II resalta las bondades de una intervención estatal en muchos casos, confirmando la idea de MM de una convergencia con el modelo del Estado de bienestar. Sin embargo el Papa avisa de la existencia de exageraciones en este modelo que llevan a lo que él denomina el "Estado asistencial". Criticando estos modelos de "Estado asistencial" Juan Pablo Il afirma que: "Al intervenir [el Estado] directamente y quitar responsabilidad a la sociedad, el Estado asistencial provoca la pérdida de energías humanas y el aumento exagerado de los aparatos públicos, dominados por lógicas burocráticas más que por la preocupación de servir a los usuarios, con enorme crecimiento de los gastos". Así Juan Pablo II parece extender la crítica que hacía a modelos colectivistas por sus consecuencias en las personas a modelos económicos con una excesiva intervención estatal. Juan Pablo II afirma claramente que estos ejemplos de "Estado asistencial" suponen un exceso que no respeta el principio de subsidiariedad. 
Frente a un Estado que pretende atenderlo todo, como propondrían algunos modelos de democracias occidentales de aquellos años, Juan Pablo II afirma que se presta una ayuda más eficaz a las personas necesitadas cuando se sabe "distinguir su exigencia humana más profunda" y cuando se ofrece un "apoyo sinceramente fraterno". Frente a la interpretación excesiva del Estado de bienestar - el Estado asistencial - que expulsaría a otros actores de la vida social, Juan Pablo Il defiende la necesidad de preservar la presencia en el campo asistencial de individuos y grupos fuera de la lógica burocrática de la ayuda estatal.

\section{I.3. El principio de subsidiariedad en las encíclicas sociales de Benedicto XVI}

Podríamos pensar que esta visión crítica de una excesiva presencia del Estado responde exclusivamente al contexto histórico de Juan Pablo II marcado por su oposición con los regímenes colectivistas. Sin embargo, esta línea de reflexión ha sido continuada en el magisterio de Benedicto XVI, lo que muestra que la intuición es más que un hecho contextual. Esta intuición puede considerarse un avance del magisterio social en su comprensión del funcionamiento de la sociedad. En el caso de Benedicto XVI, preocupado principalmente con la situación espiritual europea, su visión de la relación Estado-sociedad está muy marcada por la realidad de las democracias occidentales europeas. Esta realidad tiene gran importancia por su difusión a través del proceso de globalización. Estas democracias, a la vez que gozan de servicios de sofisticación cada vez mayor, proporcionados en muchos casos por el Estado, con frecuencia van dejando de lado valores humanos y espirituales sin buscar un recambio.

Así en su primera encíclica, Deus Caritas Est(DCE) de 2005, Benedicto XVI retomaba de manera bastante similar las intuiciones anteriores de Juan Pablo II, esta vez ya sin el contexto de la oposición de los bloques económicos de fondo. Benedicto XVI afirma que "[n]o hay orden estatal, por justo que sea, que haga superfluo el servicio del amor". Por servicio del amor entiende el servicio gratuito al prójimo realizado de manera comunitaria y orgánica. Este servicio del amor no se limita exclusivamente a las iniciativas de la sociedad civil, sin embargo es claro que la sociedad civil es un entorno privilegiado para el desarrollo de un servicio así. El Papa además subraya como un Estado que asuma demasiadas responsabilidades, y por ello se burocratice excesivamente, quita espacio a la posibilidad de desarrollar un tal servicio por amor. Por ello siempre serán necesarias iniciativas particulares que canalicen ese amor por el prójimo concreto más allá de todo programa estatal. Benedicto XVI parece reconocer una amenaza para estas iniciativas concretas en "[e]l Estado que quiere proveer a todo, que absorbe todo en sí mismo." Dicho 
Estado "se convierte en definitiva en una instancia burocrática que no puede asegurar lo más esencial que el hombre afligido - cualquier ser humano- necesita: una entrañable atención personal". Lo contrario a este exceso de Estado es un Estado que "generosamente reconozca y apoye, de acuerdo con el principio de subsidiaridad, las iniciativas que surgen de las diversas fuerzas sociales y que unen la espontaneidad con la cercanía a los hombres necesitados de auxilio". La nueva referencia al principio de subsidiariedad nos muestra como ambos papas ven el que el Estado quiera asumir excesivo protagonismo en la atención a las necesidades de los ciudadanos como un desequilibrio de dicho principio. El papa presenta a la iglesia como una de esas otras fuerzas sociales que deben poder tomar iniciativas en la sociedad.

El papa afirma la necesidad de una acción caritativa de la Iglesia donde ella sea el sujeto activo de la acción, pues esta acción es expresión de su propia naturaleza. El Papa defiende la presencia de laicos cristianos en la política como expresión de esa caridad. Pero esta presencia no puede suponer el renunciar a la acción caritativa directa de la Iglesia con la excusa de que está siendo ya cubierta por la organización asistencial del Estado.

Finalmente, en su encíclica Caritas in Veritate (CV) de 2009 Benedicto XVI hace la reflexión más completa sobre la modificación de roles de los actores sociales y sobre las aplicaciones del principio de subsidiariedad. Benedicto XVI identifica un cambio muy profundo en las relaciones de poder en la sociedad como fruto del proceso de globalización que parece poner en cuestión el rol de los Estados. Esto implica un cambio importante en la visión social de la Iglesia que se había construido en los años 60 y 70 con Juan XXIII y Pablo VI. Si aquella síntesis suponía una importante intervención del Estado para regular la economía, la actual globalización parece limitar fuertemente el papel del Estado en la economía.

Benedicto XVI defiende claramente el rol del Estado y afirma que es necesaria una "renovada valoración de su papel y de su poder". Pero esta renovada valoración ha de incluir una "mayor atención y participación en la res publica por parte de los ciudadanos" sobre todo a través de la sociedad civil. En este sentido Benedicto $\mathrm{XVI}$ resalta como las políticas sociales que se consideraban propias del Estado están viéndose cada vez más impotentes para afrontar las consecuencias sociales de los cambios económicos globales. Igualmente amenazados están organizaciones de la sociedad civil como los sindicatos.

De manera más concreta y propositiva Benedicto XVI recuerda la visión de Juan Pablo II de la sociedad como conformada por tres actores: Estado, mercado y 
sociedad civil. Esta organización de múltiples actores ha de ser respetada pues el peligro es reducir la vida económica a la acción del mercado y del Estado, lo que impediría la participación de los particulares como sociedad civil. Es principalmente desde esta participación desde dónde surgen iniciativas basadas en la fraternidad y la gratuidad, necesarias para construir una auténtica civilización económica.

Benedicto XVI llega a reconocer con claridad que la propuesta que en su día introdujera la encíclica Rerum Novarum de la intervención redistributiva del Estado en la economía, uno de los principios importantes de la enseñanza social de la Iglesia, hoy en día "se muestra incompleta para satisfacer las exigencias de una economía plenamente humana". Benedicto XVI afirma que reducir la actividad social al binomio Estado-mercado "debilita a la larga la solidaridad en las relaciones entre los ciudadanos". Es pues necesaria la presencia de formas de economía solidarias surgidas principalmente de la sociedad civil.

Benedicto XVI pide, ante los cambios de la globalización, un replanteamiento de la autoridad política. Esto no quiere decir que se prescinda de los Estados, por el contrario Benedicto XVI reconoce su papel y pide que se trabaje por establecer auténticos Estados de derecho allá donde éste no está bien desarrollado. Este es el caso por ejemplo de la mayor parte de África. Sin embargo, sí afirma que la globalización pide una forma de autoridad política que está "más repartida".

Para este replanteamiento de la autoridad política, Benedicto XVI recuerda el principio de subsidiariedad de la enseñanza social católica al que llama "expresión inalienable de la libertad humana". Para Benedicto XVI subsidiariedad no significa dejar a los individuos y grupos a su suerte, entiende este principio más bien como una ayuda a los individuos, que debe ser ofrecida "cuando la persona y los sujetos sociales no son capaces de valerse por sí mismos". Pero esta ayuda implica "siempre una finalidad emancipadora, porque favorece la libertad y la participación a la hora de asumir responsabilidades". Opone el papa la auténtica subsidiariedad al "asistencialismo paternalista", lo que recuerda a afirmaciones anteriores de Juan Pablo Il ya vistas.

Sin embargo, Benedicto XVI llama la atención sobre la necesidad de mantener el equilibrio entre dos grandes principios sociales, el principio de subsidiariedad y el de solidaridad. Para el Papa "la subsidiaridad sin la solidaridad desemboca en el particularismo social, también es cierto que la solidaridad sin la subsidiaridad acabaría en el asistencialismo que humilla al necesitado". Así en el ejercicio de esta solidaridad, en concreto en el caso de la ayuda internacional, invita a buscar la 
participación de los diferentes actores sociales "implicando no sólo a los gobiernos de los países interesados, sino también a los agentes económicos locales y a los agentes culturales de la sociedad civil, incluidas las Iglesias locales".

En su lectura más bien crítica de CV, el economista Bernard Laurent, confirma nuestra apreciación sobre la recepción por parte de Benedicto XVI del acento especial de Juan Pablo II en la iniciativa de la sociedad. Laurent acusa a Benedicto $\mathrm{XVI}$ de tener una actitud ambigua y de hacer concesiones frente a posiciones más liberales en economía. Para Laurent aunque Benedicto XVI hace referencia a la necesaria intervención del Estado en varios momentos, en el fondo muestra una cierta reserva hacia éste. Por una parte el papa parece ver al Estado como impotente frente al movimiento globalizador inspirado por el liberalismo. Pero, sobre todo, parece proponer una reforma en la forma que el Estado interviene en las políticas de redistribución para evitar un excesivo asistencialismo. En palabras de Laurent:

Él (Benedicto XVI) claramente pide una intervención legítima del Estado en el contextos de las políticas de redistribución, pero su posición sobre como reformar las maneras en que la autoridad pública interviene -que el encuentra inefectiva debido al exceso de burocracia $\left(\mathrm{Cv}_{\mathrm{V}}-60\right)$ - se inclina hacia la retórica liberal de la responsabilidad individual, y en esto de una manera más extrema que cualquiera de sus predecesores $(\mathrm{C} v-24)$.

Es posible encontrar también otras lecturas de estos trazos del pensamiento social de Benedicto XVI en CV que sean menos críticas que la de Laurent. Por ejemplo Juan Ignacio Font en su comentario a CV afirma que "la sociedad civil se propone como lugar hermenéutico "civilizado" desde el que Caritas in Veritate contempla e interpela al conjunto del sistema económico". Para Font el desarrollo humano integral que exige la encíclica supone, en sus palabras, "la integración efectiva de la sociedad civil -con sus instancias sociales, sus iniciativas emprendedoras y su creatividad cultural propias- en el conjunto del sistema económico y social". Frente a un exceso de asistencialismo por parte del Estado Benedicto XVI recuerda la invitación a una mayor participación de la sociedad del conjunto del magisterio social. Esta participación se ha de producir a través de diferentes iniciativas cívicas y a través de la iniciativa económica que canaliza el mercado. Todo esto puede verse como una buena expresión de esta lectura del sistema económico actual de ciertos países occidentales desde el lugar hermenéutico de la sociedad civil. 


\section{Una correlación crítica entre el magisterio social de la Iglesia y el pensamiento social liberal}

La crítica al papel del Estado en la economía y en la sociedad es uno de los principales rasgos de las visiones más radicalmente liberales de la economía. Aunque esta crítica se dirige a la intervención del Estado en la planificación de la economía, inevitablemente se extiende a los servicios que el Estado ofrece a los ciudadanos por requerir estos una cierta presencia e iniciativa económica de los gobiernos. La revista The Economist, revista que no oculta su adscripción liberal, en un artículo de 2010 titulado "The growth of the state: Leviathan stirs again". En este artículo llamaba la atención sobre el crecimiento del Estado en muchos países como respuesta a la crisis sintetizando muy bien las críticas más corrientes a este papel del Estado. Así afirmaba el artículo que:

Los departamentos gubernamentales son buenos cuando se trata de expandir sus imperios. Por lo tanto un Estado de bienestar que estaba diseñado para ayudar a las personas a afrontar los riesgos inevitables, como la enfermedad y la vejez, está cada vez más presente en el negocio de tratar de eliminar todo riesgo en general a través de una proliferación de burocracias sanitarias y de seguridad. Los empleados públicos son también buenos cuando se trata de proteger sus propios intereses... El sector público está sujeto a todo tipo de incentivos perversos. Los políticos usan el dinero público para "comprar" votos... los grupos de interés gastan grandes cantidades en intentar influenciar las decisiones políticas.

Es fácil percibir similitudes entre una posición así y el mayor acento que introdujo Juan Pablo II en el magisterio social basado en la iniciativa individual.

Los intentos del entorno liberal radical por co-optar las afirmaciones del magisterio social desde Juan Pablo II han sido muchos. En gran parte, estos intentos suponen una lectura descontextualizada del magisterio social del Papa que ignora deliberadamente las condiciones históricas a las cuales responde. Ya tras la publicación de la encíclica CA las reacciones al documento quisieron leerlo como un apoyo explícito de Juan Pablo II a posturas más liberales en economía. Estas fueron las reacciones de algunos neo-conservadores como Michael Novak, James Schall - Richard John Neuhaus. En su comentario a la encíclica, Daniel Finn critica duramente estas interpretaciones "ideológicas" del texto como interpretaciones selectivas que juegan en contra del deseo del papa de favorecer la subjetividad de la sociedad civil. 


\section{I. La visión del Estado de Frederik Hayek}

Si consideramos al pensamiento de Frederik Hayek como una de las principales fuentes intelectuales de las posturas económicas más liberales hoy en día, es interesante acercarse a este autor para ver como plantea este problema de la relación entre el Estado y la sociedad civil. Para evitar anacronismos, es necesario tener presente el contexto en el que Hayek se plantea la relación Estado-sociedad. En sus primeras etapas, alrededor de la Segunda Guerra Mundial, la obra políticoeconómica de Hayek quiere ser una llamada de atención sobre los peligros de la intervención del Estado en economía por medio de la planificación. Hayek rechaza tanto el colectivismo marxista como el fascismo por el desprecio de estos regímenes del individuo. A la vez, identifica en las democracias occidentales un cierto deslumbramiento ante estos regímenes que lleva a buscar imitarlos aumentando el papel planificador del Estado. Hayek quiere avisar de los peligros de una tal intervención para recuperar el auténtico valor del individuo del liberalismo clásico.

Hayek, en su obra programática de 1944 Camino de servidumbre, consigue captar el fondo del problema que la doctrina social desarrollará, en otro contexto histórico, especialmente a partir de Juan Pablo II. Hayek identifica así el peligro de que un Estado al que se confíe la dirección más completa de la economía acabe reduciendo la libertad de la sociedad y reduciendo el espacio para la iniciativa de los ciudadanos en todos los campos. En este sentido, la preocupación de Hayek no es por la eficiencia económica de la sociedad sino por la libertad efectiva de ésta. En este punto Hayek se acerca de preocupaciones propias de la Doctrina Social.

La tesis principal de Hayek es que, en sus palabras, "la libertad individual no se puede conciliar con la supremacía de un solo objetivo al cual debe subordinarse completa y permanentemente la sociedad entera". Ese objetivo único supondría planificar la totalidad de la actividad social. Algo así podría ser posible en grupos humanos pequeños como una familia o una aldea, pero en las complejas sociedades modernas una tal planificación supondría un control total de toda actividad social.

Una tal planificación lleva a que el Estado tenga que decidir cómo repartir los recursos, lo que se presta a arbitrariedades a luchas de poder por lograr el favor de los que deciden, a una politización de la vida social. Por lo tanto los esfuerzos y energías humanos no se volcarán en procesos creativos sino, en palabras de Hayek, en "inclinar en nuestro favor a la autoridad que goza de todo el poder". 
Una situación así tendría por supuesto consecuencias económicas al favorecer una tendencia al monopolio en los mercados. Pero Hayek no da tanta importancia a las consecuencias económicas como a las consecuencias políticas de un mayor papel del Estado en economía en términos de menos libertad. Estas consecuencias afectan igualmente a la dimensión cultural de la sociedad, pues el Estado se ve invitado a imponer una serie de valores culturales que favorecen los objetivos del plan. Finalmente, estos efectos negativos de la planificación económica por el Estado acaban alcanzando la vida moral de la sociedad. La toma de todas las decisiones por parte del Estado des-responsabiliza a los individuos de estas. Esta situación reduce su sensibilidad moral ante las cuestiones sociales.

Como vemos la preocupación de Hayek por las consecuencias de una excesiva intervención del Estado en economía no es sólo a nivel de eficiencia económica. Hayek se preocupa por sus efectos sobre la capacidad creativa y sobre la vida cultural y moral de la sociedad. En este sentido el análisis crítico de Hayek efectivamente se acerca mucho a las intuiciones que se expresan en las encíclicas sociales desde Juan Pablo II, aunque es necesario entender ambas posiciones integradas en su distinto contexto histórico.

Sin embargo, aunque la posición de Hayek es cercana a la doctrina social actual en su visión crítica de una excesiva presencia del Estado, no lo es en la alternativa que propone. En Camino de servidumbre Hayek esboza brevemente su propuesta de organización social. Ya en este esbozo se percibe una visión radicalmente individualista de la sociedad opuesta a la visión de la doctrina social.

Hayek termina su libro afirmando que "[e]l principio rector que afirma no existir otra política realmente progresiva que la fundada en la libertad del individuo sigue siendo hoy tan verdadero como lo fue en el siglo XIX". Hayek, por lo tanto, reconoce su inspiración en el individualismo liberal del siglo XIX. Hayek afirma que su ideal es el de una sociedad individualista, entendiendo por esta una donde no se tengan en cuenta en las decisiones los vínculos del individuo con sus conciudadanos. Para Hayek por tanto no existe nada parecido a un "bien común" que pueda ayudar a regir la vida de la sociedad. En la visión de la sociedad de Hayek el individuo debe aceptar resignadamente los efectos de los vaivenes de la economía dejada a la libre competencia, único reflejo fiel de los mecanismos de la sociedad. En palabras de Hayek "la mera conservación de todo lo que hemos logrado depende de la coordinación de los esfuerzos individuales mediante fuerzas impersonales". Por lo tanto el respeto de la libertad individual exige el dejar a la libre competencia la marcha de la economía sin mirar a las consecuencias sociales que eso pueda producir en una actitud que podríamos considerar de conformismo voluntario. 
Esta propuesta alternativa de Hayek se formula más claramente en el desarrollo posterior de su pensamiento ya en el contexto de la Europa del bienestar de la postguerra. Hayek desarrollará las ideas contenidas en Camino de servidumbre pero ahora en diálogo con la nueva realidad social. Así en su obra de 1973 Derecho, legislación y libertad, Hayek defenderá la existencia de un orden propio a las sociedades complejas modernas. Este orden, que el llamará "catalaxia" (del verbo griego katallattein, intercambiar), es un orden impersonal y ciego de la sociedad regido por los intercambios entre los individuos y el mecanismo de los precios de mercado. En palabras de Hayek, "[d]enominamos, pues, catalaxia al peculiar orden espontáneo que el mercado genera, ámbito en el cual la gente somete su conducta a las normas relativas a la propiedad, el fraude y el contrato". Esta visión de la sociedad lleva a Hayek a negar la existencia de un bien común de la sociedad o de una justicia social que pudiera juzgar la organización de la sociedad. Las relaciones en la sociedad se limitan a relaciones impersonales y mecánicas de intercambio determinadas por el mecanismo de los precios. La visión de la sociedad de Hayek, por tanto, acaba siendo directamente opuesta a la del pensamiento social de la lglesia.

Vemos así en el pensamiento de Hayek como el captar los riesgos de la excesiva presencia del Estado en la sociedad no asegura que la propuesta posterior sea la más adecuada. Esto nos ha de llevar a desconfiar de propuestas liberales a pesar de que podamos coincidir plenamente con el planteamiento inicial del problema.

\subsection{Paralelismos con el papel del Estado en Amartya Sen}

Es posible sin embargo ir más allá de las propuestas de autores más radicalmente liberales y recoger de manera más equilibrada la crítica acertada sobre el excesivo papel del Estado de la escuela liberal. Un ejemplo de esto nos lo proporciona el pensamiento de Amartya Sen. En este sentido Sen representa un ejemplo especialmente valioso, pues se trata de un autor que se presenta explícitamente como liberal y que quiere situarse en la herencia intelectual de Adam Smith. Igualmente es posible encontrar conexiones entre Sen y el pensamiento social cristiano pues participó en el simposio organizado por el Pontificio Consejo Justicia y Paz para ayudar a la reflexión previa a la encíclica CA.

Sen escribe en el contexto del final del siglo XX en el que se da un debate sobre si en ocasiones alcanzar un desarrollo económico puede exigir renunciar a libertades individuales. Sen quiere poner a la persona en el centro y mostrar como el bienestar auténtico e integral de ésta es el criterio del auténtico desarrollo. Este bienestar 
sólo puede darse en sociedades auténticamente democráticas. Sen es así perspicaz en detectar el peligro existente en políticas demasiado asistencialistas de ahogar la iniciativa de los individuos, y volverlos especialmente pasivos. Sen entiende el desarrollo como "un proceso de expansión de las libertades reales que disfrutan los individuos". Para Sen, esta definición supone primero que el auténtico desarrollo debe implicar no sólo mayor renta sino también mayor libertad (libertades como constitutivas del desarrollo). Pero, en segundo lugar, la definición implica también que la libertad es el primer instrumento para lograr mayor libertad y por lo tanto mayor desarrollo (libertad como instrumento para el desarrollo). Así el desarrollo de una sociedad es el fruto principalmente del uso activo de su libertad por parte de los individuos tomando iniciativas en sociedad. Sen llama a este uso de la libertad agency, término que la traducción española de su obra traduce por "agencia".

De esta manera, en una lectura superficial Sen se podría interpretar como contrario a la intervención del Estado en la economía, lectura que parecería converger con la postura de Hayek. Sen también ve como un grave problema una presencia del Estado que por su excesivo asistencialismo pueda sofocar las libertades e iniciativas del individuo. Una situación así supone un problema político y un problema económico a la vez pues supone paralizar uno de los motores del desarrollo: la agencia de los individuos. En el esquema de la sociedad de Amartya Sen, como en el del magisterio social, el Estado tiene como función más bien ayudar y favorecer la iniciativa libre y autónoma de los individuos sin sofocarla.

Sin embargo Sen, contrariamente a Hayek, al presentar una propuesta socioeconómica más concreta sigue reconociendo la necesidad de determinadas intervenciones del Estado en la sociedad. En este sentido, Sen parte de la idea de que es posible intervenir para ayudar a superar las situaciones de postración de los ciudadanos. A ello le conduce su análisis de las causas de la hambruna de la que fue testigo en Bengala en 1943. Esta intervención tiene para Sen un objetivo principal: asegurar las capacidades mínimas en la población que son las que permiten que las personas sean efectivamente libres. Así Sen afirma en un momento de su obra Desarrollo y libertad:

En los países en vías de desarrollo en general, es fundamental la necesidad de adoptar iniciativas públicas para la creación de oportunidades sociales. Como hemos señalado antes, los países que hoy son ricos poseen una historia bastante notable de medidas públicas relacionadas con la educación, la asistencia sanitaria, la reforma agraria, etc. La amplia difusión de estas oportunidades sociales permitió a la mayoría de los individuos participar directamente en el proceso de expansión económica.

De esta manera Sen reconoce un papel imprescindible del Estado en la sociedad asegurando las oportunidades sociales para todos (educación, sanidad...) y una 
protección social básica para todos los ciudadanos que les impida caer en la miseria. También es papel del Estado asegurar y conservar otros bienes públicos necesario para la sociedad. Finalmente, Sen también admite un papel aún más activo para el Estado en ciertas ocasiones. Afirma así Sen que ante situaciones de hambre o fuerte carestía puede ser eficaz que el Estado busca maneras de ofrecer empleo a los ciudadanos en lugar de ofrecer subsidios o ayudas. Esta es la mejor manera de producir desarrollo pues el empleo es la mejor fuente de agencia de los individuos.

Aunque el pensamiento de Amartya Sen no es perfecto y hay puntos que se pueden mejorar, el aproximarnos a él en el tema que nos ocupa es especialmente interesante. La visión de la sociedad de Sen, basada en la libertad, nos permite formular una crítica legítima a una excesiva presencia del Estado en la sociedad, como hace el magisterio social. Pero esta crítica es capaz de reconocer con la misma lógica aquellas presencias e intervenciones del Estado necesarias para el buen funcionamiento de la sociedad. Evitamos así un rechazo ideológico a la presencia del Estado que nos ciegue para valorar sus ventajas.

\section{Conclusiones}

Está claro que estamos en un momento de cambio de organización social y que hoy en día hay una mayor consideración del papel y posibilidades de la iniciativa de los ciudadanos en la sociedad, esto no ha sido siempre así. La actual sensibilidad es producto de la experiencia histórica así como del mayor conocimiento del funcionamiento de los mecanismos económicos y sociales. Sin necesidad de hablar de peligro de totalitarismo, como lo hace Hayek, hay un reconocimiento del peligro de ahogar la iniciativa y la creatividad individual cuando el Estado se hace omnipresente, des-responsabilizando a los ciudadanos de lo que ocurre en la sociedad. La mayor reserva actual a esta intervención del Estado no viene tanto por la ineficacia económica sino de los efectos morales y humanos que puede tener exceso de ésta según ha mostrado la experiencia histórica. Juan Pablo Il describe muy bien estos efectos como "emigración psicológica". El magisterio social de la Iglesia ha sabido recoger estas intuiciones y formularlas matizando el principio de subsidiariedad.

Hay que decir, sin embargo, que se trata de un tema de acentos, pues desde el comienzo la doctrina social ha pedido la intervención del Estado y a la vez ha avisado del peligro de ahogar la iniciativa de los individuos. No se puede hablar 
por tanto de un cambio en el magisterio social, sino de una respuesta a los datos que proporciona la experiencia histórica de las sociedades.

Hayek, influenciado probablemente por el contexto del auge de los totalitarismos en los años 30, exagera al identificar los peligros de lo que él llama el "planismo" en el nivel social, cultural y moral. Hay, sin embargo, que reconocer que fue visionario en reconocer estos peligros en una época donde no se ponían en cuestión fácilmente esta mayor posición del Estado. Sin embargo Hayek aprovecha esta crítica aguda para proponer un modelo alternativo que conlleva implicaciones antropológicas y sociales más que discutibles y en cualquier caso incompatibles con la visión del magisterio social. Esta alternativa de Hayek revela la visión de fondo de la posición liberal más radical sobre la sociedad y nos permite identificar sus incompatibilidades con la posición del magisterio social de la Iglesia.

La visión de Sen, paralela a Hayek al ser él también liberal pero más libre de prejuicios por su momento histórico y su contexto vital, nos muestra que se puede tener la misma preocupación por el respeto a la iniciativa y creatividad individual reconociendo igualmente el papel del Estado en fomentar esa misma iniciativa. La visión de la intervención del Estado de Sen permite compaginar los principios de subsidiariedad y solidaridad de manera bastante equilibrada como se pide en el magisterio social.

Sen y el magisterio social coinciden en pedir al Estado, para juzgar la legitimidad de su intervención, que adopte un papel de apoyo y promoción de los individuos y sus iniciativas sin sustituirlas por otras estatales. Sen nos dice que el sustituirlas o entorpecerlas supondría ir contra el desarrollo humano de una sociedad al reducir la agencia y las capacidades de esa población. Creo que este es un criterio de discernimiento para juzgar cada presencia del Estado en la sociedad sin prejuicios ideológicos previos. La pregunta que debemos hacernos es: esta presencia concreta del Estado, ¿̇ayuda a los ciudadanos a ser más autónomos y activos en la sociedad? Al plantearse esta pregunta desde sociedades occidentales con grandes Estados de bienestar bien establecidos, creo que la disposición de partida debe ser favorable a reducir esas presencias habida cuenta de los efectos nocivos que se perciben en la agencia de la sociedad.

Una actitud así de discernimiento permitiría superar el impasse actual entre una defensa ideológica del Estado y una propuesta también ideológica del liberalismo radical que quisiera reducirlo lo más posible en base a principios antropológicos muy discutibles. 
Un análisis de los límites de la presencia del Estado en las sociedades occidentales puede basarse así en el evaluar cada presencia pública en función de la manera que ayude $o$ ahogue la agencia de los individuos. En esta evaluación no hay que tener miedo de identificar una presencia excesiva y pedir su reducción. Una tal evaluación podría ayudar a reducir la insoportable carga burocrática del empresario del programa de televisión que comentábamos al comienzo del artículo sin por ello tener ideológicamente que buscar reducir la cobertura sanitaria a quienes la necesitan.

\section{Bibliografía}

CAlvez, J.-Y. (1991) La enseñanza social de la Iglesia. La economía. El hombre. La sociedad, Barcelona, Herder.

CAMACHO, I. (1991) Doctrina social de la Iglesia. Una aproximación histórica, Madrid, San Pablo.

DECK, A. F. (2005) "Commentary on Populorum Progressio (On the Development of People)" en HIMES, K., ET ALL. (ED.) Modern Catholic Social Thinking: Commentary and Interpretations, Washington D.C., Georgetown University Press, pp. 292-314.

Dubols, J.-L. y Renouard C. (2008) "Une Approche à Poursuivre... et à Dépasser": Projet $\mathrm{n}^{\circ}$ 306, pp. 12-19.

FinN, D. K. (2005) "Commentary on Centesimus Annus (On the Hundred Anniversary of Rerum Novarum)" en HIMES, K. Et ALL. (ED.) Modern Catholic Social Thinking: Commentary and Interpretations, Washington D.C., Georgetown University Press, pp. 436-466.

Font, J. I. (2009) "Sistema económico, modelos de empresa y cultural empresarial": Revista de Fomento Social n 64, pp. 655-666.

GIRAUD, G. y Dubols, J.-L. (2008) "Amartya Sen. L'économie d"acteurs capables": Projet $n^{\circ} 306$, pp. 4-11.

GonZÁleZ Fabre, R. (2005) Ética y economía. Una ética para economistas y entendidos en economía, Bilbao, Desclée de Brouwer-UNIJES. 
HAYeK, F. A. (1985) Camino de servidumbre, Madrid, Alianza Editorial.

- (1979) Derecho, legislación y libertad. El espejismo de la justicia social. Vol. 2, Madrid, Unión Editorial.

Laurent, B. (2010) "Caritas in Veritate as a Social Encyclical: A Modest Challenge to Economic, Social, and Political Institutions": Theological Studies n 71 (2010), pp. 515-544.

LÉGÉ, P. (2008) "Critique de la justice sociale selon Hayek": Projet n 303, pp. $57-62$.

MARITAIN, J. (1983) El hombre y el Estado, Madrid, Encuentro.

MiCH, M. L. (2005) "Commentary on Mater et Magistra (Christianity and Social Progress)" en HIMES, K., ET ALL. (ED.) Modern Catholic Social Thinking: Commentary and Interpretations, Washington D.C., Georgetown University Press, pp. 191-216.

OrnaghI, L., (2004) "Stato" en OrnaghI, L. (ED.), Dizionario di dottrina sociale de la Chiesa. Scienze sociali e magisterio, Milan, Vita e Pensiero, pp. 588-592.

Orobator, A. (2010) "Caritas in Veritate and Africa's Burden of (Under)Development": Theological Studies n 71, pp. 320-334.

SEN, A. (2000) Desarrollo y libertad, Barcelona, Planeta.

The ECONOmist (2010) "The Growth of the State: Leviathan Stirs Again", www. economist.com/node/15328727. 